\title{
Pathophysiological characteristics of asthma in the elderly: a comprehensive study(Abstract_要 旨）
}

$\operatorname{AUTHOR(S):~}$

Inoue, Hideki

\section{CITATION:}

Inoue, Hideki. Patho physiological characteristics of asthma in the elderly: a comprehensive study. 京都大学, 2015, 博士(医学)

\section{ISSUE DATE:}

2015-03-23

URL:

https://doi.org/10.14989/doctor.k18884

RIGHT: 
